Grant/research support from: BMS, MSD, AbbVie, Roche, Novartis, Biogen and Pfizer, Consultant of: Eli Lilly, Speakers bureau: Orion Pharma, Biogen, Pfizer, CellTrion, Merck and Samsung Bioepis, Robin Christensen: None declared, Lykke Ørnbjerg: None declared, Daniel Glinatsi: None declared, Jakob Møllenbach Møller: None declared, Mikael Boesen Consultant of: AbbVie, AstraZeneca, Eli Lilly, Esaote, Glenmark, Novartis, Pfizer, UCB, Paid instructor for: IAG, Image Analysis Group, AbbVie, Eli Lilly, AstraZeneca, esaote, Glenmark, Novartis, Pfizer, UCB (scientific advisor)., Speakers bureau: Eli Lilly, Esaote, Novartis, Pfizer, UCB, Kristian Stengaard-Pedersen: None declared, Ole Rintek Madsen: None declared, Bente Jensen: None declared, Jan Villadsen: None declared, Ellen Margrethe Hauge: None declared, Philip Bennett: None declared, Oliver Hendricks: None declared, Karsten Asmussen: None declared, Marcin Kowalski: None declared, Hanne Merete Lindegaard: None declared, Henning Bliddal Grant/research support from: received research grant fra NOVO Nordic, Consultant of: consultant fee fra NOVO Nordic, Niels Steen Krogh: None declared, Torkell Ellingsen: None declared, Agnete Nielsen: None declared, Anne Grethe Jurik: None declared, Lone Balding: None declared, Henrik Thomsen: None declared, Mikkel Ǿstergaard Grant/research support from: AbbVie, Bristol-Myers Squibb, Celgene, Merck, and Novartis, Consultant of: AbbVie, Bristol-Myers Squibb, Boehringer Ingelheim, Celgene, Eli Lilly, Hospira, Janssen, Merck, Novartis, Novo Nordisk, Orion, Pfizer, Regeneron, Roche, Sandoz, Sanofi, and UCB, Speakers bureau: AbbVie, Bristol-Myers Squibb, Boehringer Ingelheim, Celgene, Eli Lilly, Hospira, Janssen, Merck, Novartis, Novo Nordisk, Orion, Pfizer, Regeneron, Roche, Sandoz, Sanofi, and UCB DOI: 10.1136/annrheumdis-2020-eular.2099

\section{FRI0020 \\ CLINICAL TREATMENT RESPONSE STILL DOES NOT MATCH PATIENT REPORTED IMPROVEMENT, EVEN IN EARLY RHEUMATOID ARTHRITIS}

S. Pazmino ${ }^{1}$, A. Lovik ${ }^{2}$, A. Boonen ${ }^{3}$, D. De Cock ${ }^{1}$, V. Stouten ${ }^{1}$, J. Joly ${ }^{4}$, D. Bertrand ${ }^{1}$, R. Westhovens ${ }^{1,4}$, P. Verschueren ${ }^{1,4}$ on behalf of CareRA Study Group. ${ }^{1} \mathrm{KU}$ Leuven, Development and Regeneration, Leuven, Belgium; ${ }^{2} \mathrm{KU}$ Leuven, Leuven Biostatistics, Leuven, Belgium; ${ }^{3}$ Maastricht UMC, Maastricht, Netherlands: ${ }^{4}$ University Hospitals Leuven, Rheumatology, Leuven, Belgium

Background: Commonly used disease activity scores in rheumatoid arthritis (RA) include one patient reported outcome (PRO) -the patient's global health assessment (PGA). Exploratory factor analysis (EFA) was performed on data from the 2 year Care in early Rheumatoid Arthritis (CareRA) trial to explain the evolution of disease burden extracting 3 factors. ${ }^{1}$

Objectives: To assess the evolution and relative responsiveness over time of clinical, laboratory and patient assessments included in composite scores, together with other PROs like pain, fatigue and functionality in patients with early $\mathrm{RA}$ ( $\leq 1$ year) treated to target (T2T) within the CareRA trial.

Methods: DMARD naïve patients with early RA $(n=379)$ were included, randomized to remission induction with COBRA-like treatment schemes $(n=332)$ or MTX monotherapy $(n=47)$ and T2T.

Components of disease activity scores (swollen/tender joint count (S/TJC), C-reactive protein (CRP) or erythrocyte sedimentation rate (ESR), and physician $(\mathrm{PhGH})$ or patient (PGA) global health assessment), pain and fatigue (both on 0-100 scale) and HAQ were recorded at every visit.

Missing data was handled with multiple imputation $(n=15)$. Clustering was removed with multiple outputation $(n=1000)$, then each of the 15000 datasets was analyzed by EFA with principal component extraction and oblimin rotation. The analyses were combined after re-ordering the factors by maximizing factor congruence. The 3 extracted factors and their individual components (with their loadings) were: 1 . Patient containing PGA $(0.87)$, pain $(0.86)$, fatigue $(0.90)$ and HAQ (0.5) 2.Clinical with SJC (0.92), TJC (0.89) and PhGH (0.76) and 3.Laboratory with $\operatorname{CRP}(0.87)$ and ESR (0.78). ${ }^{1}$ (Pazmino, ACR 2019 abstract, Table 3) Afterwards, variables were first normalized to a $0-1$ scale, then multiplied -weighted- by the factor loadings previously obtained. ${ }^{1}$ For each Patient, Clinical and Laboratory severity score, the weighted variables belonging to each score were summed together and then re-scaled to 0-1 (higher values suggest more burden).

The percentage (\%) improvement from baseline to week 104 and the area under the curve (AUC) across time points were calculated per factor.

Differences in \% improvement and AUC were compared between patients not achieving and achieving early and sustained (week 16 to 104) disease activity score remission (DAS28CRP <2.6) with ANOVA. Bonferroni correction was used for multiple testing.

Results: Severity scores of Patient, Clinical and Laboratory factors improved rapidly over time (Figure 1). In patients achieving sustained remission $(n=122)$, Patient, Clinical and Laboratory scores improved 56\%, 90\% and $27 \%$ respectively. In patients not achieving sustained remission $(n=257)$ the improvement was $32 \%, 78 \%$ and $9 \%$ respectively ( $<<0.001$ only for clinical improvement).

Patients in CareRA who achieved sustained remission had an AUC of 15.1, 3.4 and 4.7 in Patient, Clinical and Laboratory scores respectively, compared to 32.3
10.0, and 7.2 in participants not achieving sustained remission $(p<0.001$ for all comparisons).

Conclusion: Patient, Clinical and Laboratory severity scores improved rapidly over time in patients achieving rapid and sustained disease control. However overall, Patient burden seemed not to improve to the same extent as Clinica burden. Patient's unmet needs in terms of pain, fatigue, functionality and overall well-being should thus be given more attention, even in patients in sustained remission.

References:

[1] Pazmino S, et al. Including Pain, Fatigue and Functionality Regularly in the Assessment of Patients with Early Rheumatoid Arthritis Separately Adds to the Evaluation of Disease Status [abstract]. ACR. 2019.

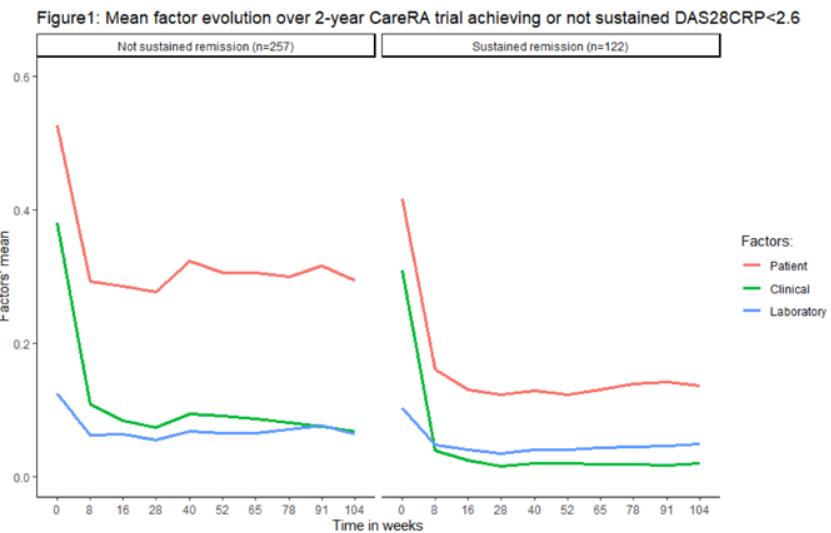

Disclosure of Interests: Sofia Pazmino: None declared, Anikó Lovik: None declared, Annelies Boonen Grant/research support from: AbbVie, Consultant of: Galapagos, Lilly (all paid to the department), Diederik De Cock: None declared Veerle Stouten: None declared, Johan Joly: None declared, Delphine Bertrand: None declared, Rene Westhovens Grant/research support from: Celltrion Inc Galapagos, Gilead, Consultant of: Celltrion Inc, Galapagos, Gilead, Speakers bureau: Celltrion Inc, Galapagos, Gilead, Patrick Verschueren Grant/research support from: Pfizer unrestricted chair of early RA research, Speakers bureau: various companies

DOI: 10.1136/annrheumdis-2020-eular.2116

\section{\begin{tabular}{|l|l}
\hline FRI0021 & SHOULD WE USE GLUCOCORTICOID IN EARLY
\end{tabular} RHEUMATOID ARTHRITIS?: RESULTS AT 5 YEARS FROM THE ERA LOUVAIN BRUSSELS COHORT}

E. Sapart ${ }^{1}$, T. Sokolova ${ }^{1}$, S. De Montjoye ${ }^{1}$, S. Dierckx ${ }^{2}$, A. Nzeusseu Toukap ${ }^{1}$, A. Avramovska ${ }^{1}$, B. Lauwerys ${ }^{1}$, P. Durez ${ }^{1}{ }^{1}$ Cliniques Universitaires Saint-Luc Université catholique de Louvain (UCL) - Institut de Recherche Expérimentale et Clinique (IREC), Rheumatology, Bruxelles, Belgium; ${ }^{2} \mathrm{CHU}$ Mont-Godinne, Rheumatology, Yvoir, Belgium

Background: The EULAR recommendations, updated in 2016, propose the initiation of glucocorticoid (GC) therapy in combination with cDMARDs background therapy for every patient with early rheumatoid arthritis (ERA). ${ }^{1}$

Objectives: The aim of this study is to evaluate the proportion of patients with ERA who have been treated with GC in daily practice, to analyse the baseline characteristics of these patients, and to assess the clinical benefit and side effects of GC during 5 years of follow-up.

Methods: We included patients with ERA from the UCLouvain Brussels cohort who met the ACR/EULAR 2010 classification criteria and were naïve to cDMARDs. Treatments were initiated based on the decision of a senior rheumatologist. We retrospectively collected patient characteristics prior to the introduction of cDMARDs with or without GC. Efficiency and serious adverse events were analysed at 6 months, 1 year, 3 years and 5 years.

Results: Data from 474 eligible ERA patients were collected. The average age of the population is 48.9 years. $70.5 \%$ of the patients are women. $27.3 \%$ are smokers and $68.8 \%$ are positive for anti-citrullinated protein antibody (ACPA).

178 patients (37.7 \%) initiated GC compared to 294 patients $(62.3 \%)$ who received only NSAIDs and/or analgesics in combination with cDMARDs.

At baseline, the elevation of CRP is the main factor that favors the initiation of GC (CRP 2.9 vs $2.0 \mathrm{mg} / \mathrm{dl}, \mathrm{p}=0.015)$ followed by smoking habits $(34.2 \%$ vs $23.3 \%$, $p=0.018)$, the absence of ACPA $(37.2 \%$ vs $27.6 \%, p=0.037)$, the prescription of methotrexate as a monotherapy $(70.6 \%$ vs $50.5 \%, p<0.001)$, and the age (50.6 vs $48.0, p=0.050$ ). Other parameters such as swollen joint count, tender joint count, DAS28-CRP, HAQ or baseline erosion were similar between groups. 